\title{
Canadian doctor led bombing response at a Boston hospital
}

I t was just after 3 pm on Monday, Apr. 15, when Dr. Ron Walls' office and cell phones began ringing simultaneously. His assistant's phone was also sounding. Then a banner alert from USA Today slid across his phone's screen, and he knew it was real.

Brigham and Women's Hospital had twice rehearsed their response to a bomb exploding at a mass gathering. Now it had actually occurred at the finish line of the Boston Marathon. Seconds later, Walls, the hospital's chair of emergency medicine and a transplanted Canadian, heard the sirens go off.

"I've never heard anything like it," Walls told CMAJ in an interview on Apr. 16. "It was as if every vehicle with a siren turned its siren on and started moving at the same time."

Walls' office is a block from the emergency department (ED). Before he even received any more information about the extent of the casualties, the Prince George, British Columbia-born doctor began walking up the hill to the department. He dialed the hospital's medical director of disaster response as he went. Walls knew his colleague was on duty at the medical tent at the finish line, along with four residents.

"I'll have to call you back," the disaster response physician told Walls. Later, Walls learned the doctor was being herded from the tent to another area to respond to victims after the second of the two bomb blasts that injured more than 170 people and left 3 dead.

Meanwhile, on the ground at the site of the blast, Boston's Emergency Medical Services (EMS) group was triaging patients, coordinating field care and dispatching casualties to Brigham and four other level-one trauma centres in Boston.

At Brigham, Walls hung up from calling his colleague and entered the

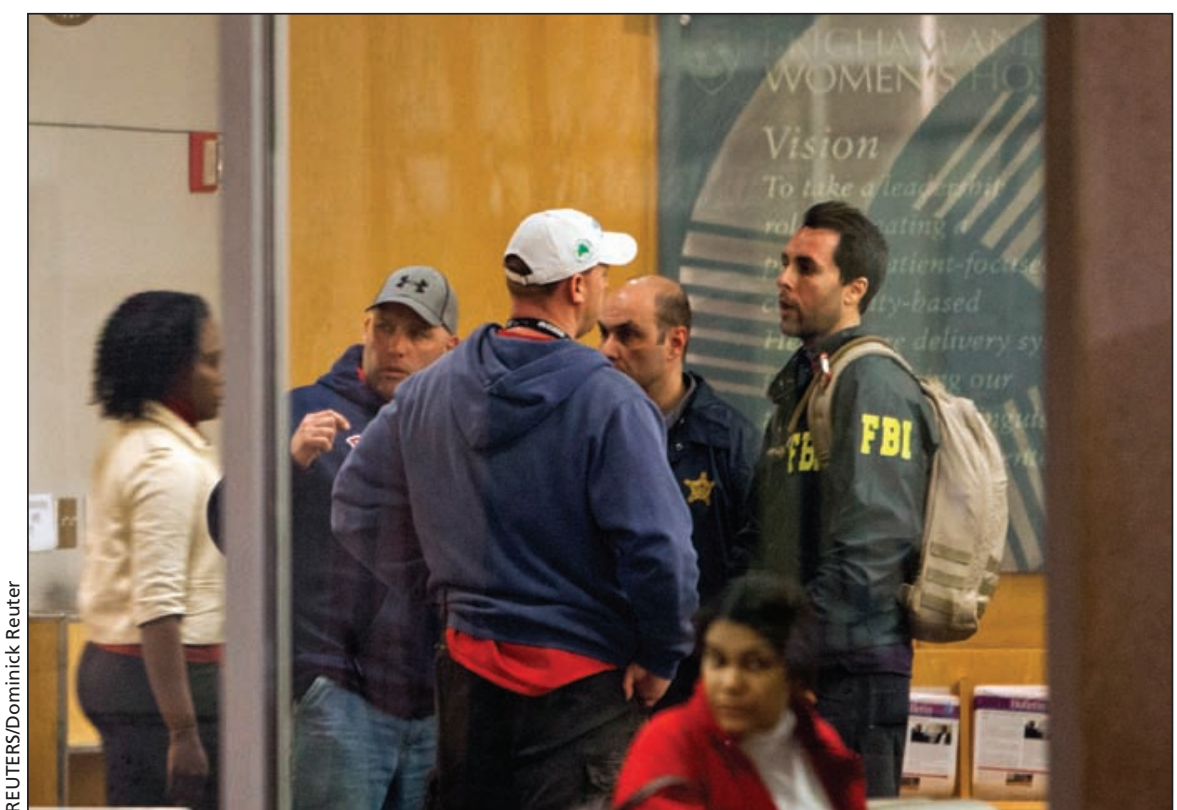

FBI officers stand guard at Brigham and Women's Hospital in light of the possibility that the hospital would become a secondary target after two bombs exploded at the Boston Marathon in Boston, Massachusetts Apr. 15, 2013.

doors of the emergency department as the first ambulances pulled up. As the coordinator of disaster response for the emergency department, Walls' first job was to ensure existing patients in the ED were admitted to in-patient units. Simultaneously, he had to clear and prepare capacity in the hospital's 42 operating rooms, and assemble trauma teams.

In the first hour after the blast, Brigham and Women's received 28 patients, many suffering from severe blast injuries to their lower extremities. There were shrapnel wounds, including a penetrating head injury and a penetrating neck injury, patients with injuries to their ear drums from the blast, and others with smoke inhalation and burns. The most serious injuries were life-threatening.

"We had patients with very extensive lower extremity injuries — large pieces of their muscle and skin and bone missing from the blast," says Walls. There were also "very bad fractures — the type of fracture you can only get with a tremendous amount of force."

Three more patients arrived subsequently. Nine of the patients needed to go to the operating room immediately. Walls had seven operating rooms cleared and ready within minutes.

As Walls oversaw the hospital's disaster response plan in the ED, another Canadian - Dr. Emily Aaronson, a second-year resident at Brigham and a graduate of McMaster University in Hamilton, Ontario — was pulled into the drama. Within an hour of starting her shift, the Toronto native was working on teams treating three seriously injured patients. All had comminuted, open fractures, the bones splintered or crushed, with large portions of muscle exposed. Bleeding copiously, the patients needed blood products and quick attention from orthopedic surgeons.

"I had seen an open comminuted fracture - I certainly hadn't seen bilateral open comminuted fractures with partial amputations," Aaronson told 
CMAJ. "I've never seen the volume of those types of injuries [before]."

Inside a smaller room, caring for her patients, Aaronson was able to forget that the traumatic injuries she was working on were caused by someone who deliberately filled homemade devices with nails and ball bearings intended to do maximum harm. That changed when she finished with one patient and moved out into the main ED to tend to another one or to get supplies.

The sheer number of medical personnel, paramedics and police officers, and the noise level from the 10 trauma teams working simultaneously was a forcible reminder that this was no ordinary holiday Monday in the Brigham ED.

"At that point you would start to understand how different this was from any other day," Aaronson says.

But neither Walls nor Aaronson had time to feel sad, or afraid. In the back of their minds was the possibility they'd rehearsed - that the hospital could become a secondary target or another bomb could go off, sending more casualties through their doors.

"We didn't want the providers at the bedside to worry about that, but we had an immediate security response, including the police department, to protect the hospital against any secondary target," says Walls. "We also brought in devices to immediately detect radiation and make sure there wasn't any contamination, so it wasn't a dirty bomb."

At the peak of the incident, when the hospital was operating at capacity, Walls had five fresh trauma teams suited up and waiting for additional casualties. He orchestrated the work of the individual trauma teams, prioritizing the patients who went to the operating room, in steady contact with the hospital's overall disaster response coordinator.

By late evening, when all of the patients had been treated and 16 were discharged, Walls and his staff began a round of debriefing and counselling sessions for staff that continued the next day.

All told, Brigham and Women's treated 31 patients aged 16 to 65 . In the 28 years that Walls has been an emergency department physician - 19 and a half of them in Boston - he says the bombing was the biggest mass casualty event he has experienced. The hospital's sister campus at Brigham and Women's Faulkner Hospital treated another 13 patients, 4 of whom went immediately to the operating room and 1 of whom was critical.

"I have never seen anything like this," says Walls, who is the former head of the Division of Emergency Medicine at the University of British Columbia in Vancouver. "What's unique about it is getting so many patients with such bad injuries simultaneously."
Few of the surgeons, with the exception of those who worked in Haiti in the aftermath of the 2010 earthquake, had seen blast and crush injuries on this scale, Walls added.

Walls credits the proximity of the EMS services already assembled for the Boston Marathon, as well as the hospital and the city's disaster preparedness response, with saving multiple lives. "We had drilled this exact scenario, this idea of having a bomb going off in a mass gathering in town," says Walls. "Nobody is ever prepared for this, but we were prepared."

Even so, Walls had no idea how well a drill would translate in practice. The day after the bombing, Walls was enormously proud of his staff, from Aaronson and the other residents to the nurses, X-ray technicians, housekeepers, and the staff who registered and transported patients.

"The fact that each of those patients got a level of care that they would have gotten if they were the only patient that arrived, is really amazing," Walls says.

The emergency preparation that Brigham and Women's Hospital engaged in was essential, he emphasizes. "I would just suggest to people that if they think these drills are silly or unnecessary or that this can't happen - it can happen." — Laura Eggertson, CMAJ

CMAJ 2013. DOI:10.1503/cmaj.109-4471 